\title{
PHOTOGRAMMETRY AND REMOTE SENSING: NEW GERMAN STANDARDS (DIN) SETTING QUALITY REQUIREMENTS OF PRODUCTS GENERATED BY DIGITAL CAMERAS, PAN-SHARPENING AND CLASSIFICATION
}

\author{
Ralf Reulke $^{\mathrm{a}, *}$, Sven Baltrusch ${ }^{\mathrm{b}}$, Andreas Brunn ${ }^{\mathrm{c}}$, Klaus Komp ${ }^{\mathrm{d}}$, Wolfgang Kresse ${ }^{\mathrm{e}}$, Maria von Schönermark ${ }^{\mathrm{f}}$, Volker Spreckels ${ }^{\mathrm{g}}$ \\ ${ }^{\text {a } H u m b o l d t-U n i v e r s i t a ̈ t ~ z u ~ B e r l i n, ~ U n t e r ~ d e n ~ L i n d e n ~ 6, ~} 10099$ Berlin, Germany - reulke@informatik.hu-berlin.de \\ ${ }^{\mathrm{b}}$ Amt f. Geoinformation, Vermessungs- u. Katasterwesen M-V, Lübecker Str. 289.19059 Schwerin - sven.baltrusch@laiv-mv.de \\ ${ }^{\mathrm{c}}$ RapidEye AG, Molkenmarkt 30,14776 Brandenburg, Germany - brunn@rapideye.net \\ ${ }^{\mathrm{d}}$ EFTAS Remote Sensing Transfer of Technology, Oststrasse 2-18, 48145 Muenster, Germany - klaus.komp@eftas.com \\ ${ }^{\mathrm{e}}$ Hochschule Neubrandenburg, Brodaer Straße 2, 17033 Neubrandenburg - kresse@hs-nb.de \\ ${ }^{\mathrm{f}}$ German Aerospace Center, GSOC, Münchner Straße 20, 82234Wessling, Germany - maria.schoenermark@dlr.de \\ ${ }^{\mathrm{g}}$ RAG Aktiengesellschaft, BG G2, Shamrockring 1, 44623 Herne, Germany - volker.spreckels@rag.de
}

\section{ISPRS and OGC}

KEY WORDS: standard, specification, sensor, metadata, calibration, implementation

\begin{abstract}
:
10 years after the first introduction of a digital airborne mapping camera in the ISPRS conference 2000 in Amsterdam, several digital cameras are now available. They are well established in the market and have replaced the analogue camera. A general improvement in image quality accompanied the digital camera development. The signal-to-noise ratio and the dynamic range are significantly better than with the analogue cameras. In addition, digital cameras can be spectrally and radiometrically calibrated.

The use of these cameras required a rethinking in many places though. New data products were introduced. In the recent years, some activities took place that should lead to a better understanding of the cameras and the data produced by these cameras. Several projects, like the projects of the German Society for Photogrammetry, Remote Sensing and Geoinformation (DGPF) or EuroSDR (European Spatial Data Research), were conducted to test and compare the performance of the different cameras.

In this paper the current DIN (Deutsches Institut fuer Normung - German Institute for Standardization) standards will be presented. These include the standard for digital cameras, the standard for ortho rectification, the standard for classification, and the standard for pan-sharpening. In addition, standards for the derivation of elevation models, the use of Radar / SAR, and image quality are in preparation.

The OGC has indicated its interest in participating that development. The OGC has already published specifications in the field of photogrammetry and remote sensing. One goal of joint future work could be to merge these formerly independent developments and the joint development of a suite of implementation specifications for photogrammetry and remote sensing.
\end{abstract}

\section{THE DIN STANDARDS COMMITTEE NA005-03-02 "PHOTOGRAMMETRY AND REMOTE SENSING"}

The German Institute for Standardization (DIN) has a long tradition in defining technical terms and in establishing quality requirements of products or procedures. The standards in photogrammetry and remote sensing are arranged in terms and definitions and in a series of quality requirements of procedures and outputs:

The basic standard DIN 18716 "Terms and definitions in photogrammetry and remote sensing" from the mid-90s has been completely revised. Several terms related to film/filter techniques of analogue photogrammetry have been eliminated. Also the former differentiation between picture and image which discriminated between the airborne and the spaceborne products has been updated to "image" and "image data" to acknowledge the basic identity of digital sensor systems. This revision of terms gave room to incorporate new terms related to sensor properties, data quality, data analysis, classification methods, metadata and quality issues. With regard to the globalization of knowledge, all the terms are promulgated not only in German but also in French and English and alphabetic indices in all three languages are included. Now, the actual German standard DIN 18716 : 2012 is published to the professional community in the scope of providing best comprehension between science, industry and customers.

The related series of standards provides quality requirements for products and procedures in photogrammetry and remote sensing and are available under code DIN 18740. While the standards DIN 18740-1 and -2 dealing with analogue aerial cameras and analogue/digital conversion using film scanners have been withdrawn, the enduring standards refer to orthophoto production (DIN 18740-3), digital cameras (DIN 18740-4), land use classification (DIN 18740-5), and further new data products. The goal of these activities was always to support users in defining their requirements in invitations for tender and service contracts by making available specifications for products and services.

The DIN Standards Committee NA005-03-02 AA "Photogrammetry and Remote Sensing" consists of representatives from authorities and administrations, universities and colleges, and private companies. Within this committee project-oriented

\footnotetext{
* Corresponding author.
} 
working groups were set up, in which specialists temporarily participate/d for the respective standardization projects.

Participation in the DIN standardization committee is voluntary and is coordinated by a chairman. In addition to the ad-hoc meetings of the working groups, two meetings of the Committee are held per year. The working committee is still open to new volunteers. International activities are integrated into the standardization processes.

Both Government and industry suggest topics that lead the development and application of standards. The standards facilitate the customer - contractor relationship by clear definitions of the initial situation and an indication of quality measures. An appropriate form in the standard DIN 18740 formalizes this relationship.

In the working committee, current and pressing problems of government and industry will be picked up and discussed (e.g. in connection with the DIN 18740-6 standards project). Another example is the participation in evaluations of current digital cameras(DIN 18740-4) in cooperation with EuroSDR and DGPF.

Standards support teaching at universities, because they compress the technical basis in a comprehensive way.

This paper is organized as follows: Sections 2 and 3 introduce the DIN 18740 and 18716 standards, section 4 mentions some recent activities, and section 5 gives some conclusions. Access to the cited standards is possible over the internet. The web links are collected in the references section.

\section{DIN 18740 STANDARDS SERIES}

The series of standards, DIN 18740, specifies requirements for quality photogrammetric products. The following have been published:

- DIN 18740-1:2001-11, Photogrammetric products - Part 1: Requirements for aerial survey and aerial analogue photo (withdrawn without replacement)

- DIN 18740-2:2005-02, Photogrammetric products - Part 2: Requirements for the scanned aerial photo (withdrawn without replacement)

- DIN 18740-3:2003-10, Photogrammetric products - Part 3: Requirements for the orthophoto.

- DIN 18740-4:2007-09, Photogrammetric products - Part 4: Requirements for digital aerial cameras and digital aerial photo (is currently being revised)

Currently in progress are:

- DIN 18740-5, Photogrammetric products - Part 5: Requirements for the classification of optical remote sensing data (Complete, will be published by August 2012)

- DIN 18740-6, Photogrammetric products - Part 6: Requirements for digital elevation models (in preparation).

- DIN 18740-7, Photogrammetric products - Part 7: Requirements for data fusion process (in preparation).

Descriptions of the 18740 standards series are given below.

\subsection{DIN 18740-3: Requirements for the Orthophoto}

Digital orthophotos are the geometric and semantic basis for the preparation and updating of maps, the collection and updating of topographic base data, and the data link in geographic information systems. They also serve as an interpretation and planning assistance in various fields.

This standard applies to digital orthophotos from aerial photographs and orthophoto derived products. It is used to define the quality requirements of the digital orthophoto and orthophoto products and to describe the sub-processes and individual variables which determine the quality of these products.

The digital images can either be a product derived from analogue / digital conversion of analogue-airborne photos or recorded from digital aerial cameras directly.

Using simple definitions, the basic quality parameters, e.g. the geometric resolution of the digital orthophotos, are described, and requirements on the underlying terrain model are defined. A special section focuses on the basics for the generation of "true orthophoto". The last chapter deals with the examination of digital orthophoto products. In an appendix, a specification for orthophoto projects is proposed.

\subsection{DIN 18740-4: Requirements for digital aerial cameras and digital aerial photo}

In accordance with the Orthophoto requirements of DIN 187403, DIN 18740-4 (quality requirements for photogrammetric products) focuses on digital photogrammetric cameras for aerophotogrammetry and the image data taken by airborne cameras. Digital imaging systems and their products, the digital images, differ fundamentally from conventional analogue systems and products. The difference is primarily due to discrete image signals as opposed to continuous image signals of the classical analogue film-based aerial camera and the differences in the photo-sensitive elements, i.e. the silicon detector and the film.

A digital aerial camera is a sensor including the camera itself as well as the platform, the positioning system, the photo flight navigation, and data storage.

The resulting digital image, compared to a photographic image, generally has different characteristics. It can be transmitted without loss and is the basis for traditional stereo photogrammetric applications, quantitative remote sensing, and visualization tasks.

After same fundamental definitions, the basic requirements for a digital camera system are introduced. Requirements related to geometric accuracy, radiometric quality, platform stabilization, optics, and detectors are set. An important part is the requirements for geometric and radiometric calibration. The last chapter deals with the digital airborne image. In an appendix, a specification for an aerial survey project with digital cameras is proposed.

\subsection{DIN 18740-5: Requirements for the classification of optical remote sensing data}

This standard applies to land cover classification based on multispectral aerial and satellite image data produced using digital optical sensors (area or line scan cameras). These sensors have to fulfill radiometric and geometric metrological requirements.

Satellite-based sensors can now provide geometric resolutions previously reserved to the aerial cameras. With the introduction of digital aerial cameras, the radiometric analysis methods for these cameras approximate the former satellite methods. Therefore, the previous distinction between airborne and spaceborne sensors looses its significance.

Due to the high geometrical resolution of these digital systems, new algorithms and methods for the analysis and interpretation of image data are introduced, in particular in computer-based classification and object recognition.

Digital imaging satellite sensors are, unlike analogue aerial cameras (film-based) which are usually absolutely calibrated. The radiometric calibration information allows a conversion of the image's grey value (DN = "Digital Number") to absolute radiance. Due to the large distance between sensor and object, 
the data of spaceborne cameras are usually corrected for the influence of the atmosphere.

The possibility to create images calibrated to absolute radiances and the combination of the properties of high geometric quality with the radiometric standards of earth observation systems opens new opportunities for the creation of derivative products. Classification requires a clear definition and description of the objects to be classified from the perspective of the user. This means an object must be describable and identifiable using multi-spectral and structural features in the image. Optionally, multi-temporal object properties (e.g., increase or decrease of a feature value in a specified time interval) can also be classified. The classification process, in a strict sense, implements the mapping of objects derived from the image data on the technical, application-specific object definitions. Classification requires a pre-processing of the image data to produce a comparable data quality, extraction, processing, and provision of reference data and additional information as well as some post-processing.

DIN 18740-5 covers three main topics:

- requirements for sensors and settings

- requirements of algorithms and procedures

- accuracy requirements

Active sensors (like radar and laser scanners) are not considered.

\subsection{DIN 18740-6: Requirements for Digital Elevation Models}

This standard applies to the production of digital elevation models prepared using terrestrial, airborne, or satellite-based recording methods. These sensors have to meet high geometrical requirements. The standard covers both digital terrain models and digital surface models. Elevation models are used in all geo-related tasks of the national survey, environmental management, prospecting, and archaeology.

The three-dimensional point set of a digital elevation model (DEM) can be detected by various methods: digitization of analogue sources using digital photogrammetric techniques, airborne laser scanning, etc.

The method finally used depends on the project definition, the required accuracy, point density, and economic cost.

The required supplementary elements like mass points or terrain characteristic structural elements for the description of DEM have to be set task-specific.

Surface modelling depends on a mathematical post-processing approach including the choice between the interpolation method or the method of meshing. The third dimension is increasingly important in the performance of geo-related tasks. The preconditions of this application are determined by the accuracy requirements and, consequently, the class membership.

DIN 18740-6 covers three main topics:

- recording / data collection methods

- classification of DEM

- products derived from DEM data sets and their practical application

In this standard, bathymetric sensors (soundings) are not considered.

\subsection{DIN 18740-7: Requirements for PAN- sharpening}

This standard shall apply to image data generated by data fusion techniques. The merged image data is the basis for applications in photogrammetry, cartography, and remote sensing.

To improve the measurement accuracy and thus to increase the number of usable sensors, it is useful to merge spectral data from different sensors to obtain an improved geometric and radiometric spectral data base for further digital processing.

In photogrammetry and remote sensing, a variety of additional applications for fusion technology are used:

DIN 18740-6 covers three main topics:

- resolution enhancement

- fusion of image and distance data (orthophotos)

- monitoring (change detection, object tracking / tracking) with multi-sensor systems

- orientation (a combination of GPS, IMU, etc)

- integration of distributed data and mobile sensors on the basis of geo-sensor networks, sensor swarms, pattern, and event detection in distributed spatial data(bases)

This standard applies to imaging sensors and specifies requirements for methods of Pan-sharpening, the fusion of lowresolution multispectral data with panchromatic higherresolution data. When combining data from different sensors, the exact co-registration of the different records is of crucial importance.

\section{DIN 18716 STANDARDS SERIES}

The series of standards DIN 18716 shall apply to the photogrammetric analysis. It establishes certain terms and definitions for its unification. The original three parts are:

- DIN 18716-1:1995-11, Photogrammetry and remote sensing -Part 1: Basic concepts and specific concepts of photogrammetric analysis

- DIN 18716-2:1996-07, Photogrammetry and remote sensing -Part 2: Specific terms of the photogrammetric analysis

- DIN 18716-3:1997-07, Photogrammetry and remote sensing -Part 3: Terms used in remote sensing

These terms have been evaluated taking into account the change from analogue to digital photogrammetry and have been revised and summarized in

- DIN 18716, Photogrammetry and Remote Sensing Definitions.

The period for objection has passed. An updated version is due for release in August 2012.

\section{UPCOMING STANDARDIZATION PROJECTS}

\subsection{Standardization Project "Image Quality"}

In the past 20 years, a large effort has been taken to characterize the image quality of remote sensing systems. Such definitions are important for the evaluation of image products. The image quality can only be measured by the quality of the final product (e.g. after object detection, classification, etc.). One option was to use the National Image Interpretability Rating Scales (NIIRS) since NIIRS is related to object detection. From an engineering standpoint, a task-based scale, like NIIRS, is not well suited because it cannot be derived from the fundamental sensor and scene behaviour. Therefore, the aim of this standard is to derive an image quality criterion based on the physical characteristics of sensor and scene. One approach (Jahn, 2012) is to assess the image quality by comparing the output of the real sensor with the output of an ideal sensor based on a local mean squared error (LMSE).

\subsection{Standardization Project "Radar Remote Sensing"}

Radar systems have a number of advantages. Unlike passive optical sensors, active radar sensors can also record data at night and under mostly cloudy conditions. Moreover in recent years, 
many new sensors were launched into space so a large amount of historical and current data will be available in the near future. In the meanwhile commercial applications like the interferometric recording of ground movements in German mining areas have been developed (Walter et. Al., 2009). . In ESA's GMES project, Terrafirma, a ground deformation detection and monitoring service called Wide Area Product (WAP) is under development by the German Aerospace Center (DLR) based on Persistent Scatterer Interferometry (PSInSAR). Fusion of image data is also used for change detection using image processing methods.

The two key advantages of radar systems are: They can achieve an outstanding spatial accuracy of the data (interferometry), and they are almost independent from weather conditions. The disadvantages are complex and extensive data processing requirements, interpretability of the data, and strong BRDF (Bidirectional Reflectance Distribution Function) effects.

There are several bands or channels that are used for different applications. With the X-band, high spatial resolution can be achieved while L-band data can provide subsurface ground information by penetrating into the ground below the surface.

In particular, the standard deals with the following topics:

- $\quad$ sensors (Space \& Aircraft Sensors)

- $\quad$ algorithms and processing strategies

- influence of elevation models, corrections / adverse effects, reference data (corner reflectors), persistance scatterer (accuracy / correlation to ground reference measurements)

\section{CONCLUSION}

The standardization project is well accepted in the community. It supports the preparation, execution, and evaluation of commercial and scientific projects. At the same time, international projects are supported.

The approach of the German Standardization Institute is serving the transfer of knowledge and best practise from the scientific research results towards practical application in administration and geomatic service industry. The standards developed also serve as the official specifications for invitations to tender of the public cartography administrations in relation to the service industry in photogrammetry, remote sensing, and geomatics.

\section{REFERENCES}

\section{References from Journals:}

Jahn, H., Reulke, R., 2012. A sensor-based approach to image quality. $P F G, 2012(1)$, pp. 19-27.

Walter, D.; Wegmueller, U.; Spreckels, V.; Hannemann, W.; Busch, W.: Interferometric monitoring of an active underground mining field with high-resolution SAR sensors. In: ISPRS Hannover Workshop 2009, WG I/2, I/4, IV/2, IV/3, VII/2, Hannover, Germany, June 2 - 5, 2009.

\section{References from websites:}

DIN 18740-3:2003-10. Photogrammetrische Produkte - Teil 3: Anforderungen an das Orthophoto. http://www.beuth.de/de/norm/din-18740-3/65002443 (14 April 2012).

DIN 18740-4:2007-09. Photogrammetrische Produkte - Teil 4: Anforderungen an digitale Luftbildkameras und an digitale
Luftbilder. http://www.beuth.de/de/norm/din-187404/98487271 (14 April 2012).

DIN 18740-5:2011-08. Photogrammetrische Produkte - Teil 5: Anforderungen an die Klassifizierung optischer Fernerkundungs. http://www.beuth.de/de/norm-entwurf/din18740-5/143772133 (14 April 2012).

DIN 18716:2011-08. Photogrammetrie und Fernerkundung Begriffe. http://www.beuth.de/de/norm-entwurf/din18716/143772013 (14 April 2012).

Terrafirma: http//www.terrafirma.eu.com (26 April 2012) 